\title{
Gestão democrática e militarização do ensino: reflexões a partir de um estudo de caso
}

\author{
Democratic management and militarization of education: \\ reflections from a case study \\ Gestión democrática y militarización de la enseñanza: \\ reflexiones de un estudio de caso

\section{CAROLINA BARREIROS DE LIMA \\ NATALIA BARBOZA NETTO JANAINA MOREIRA PACHECO DE SOUZA}

Resumo: $\mathrm{O}$ artigo aborda a gestão democrática no ensino público, problematizada a partir de pesquisa realizada em uma instituição militar de ensino do Rio de Janeiro. Um estudo de caso delineado em 2017, subsidiado por fontes documentais, entrevistas e observações apontou limites para esse processo em uma escola com características tão peculiares. Análises pautadas nos modelos de organização tensionaram a concretização de uma efetiva gestão democrática nesse espaço, fato que vai de encontro à proposta de criação e expansão de escolas cívico-militares de educação básica, instituída pela atual governança presidencial brasileira e apontada pelo Decreto $n^{\circ}$ 9.465/2019.

Palavras-chave: Gestão democrática. Militarização do ensino. Teoria organizacional.

Abstract: The article discusses the democratic management in public education, problematized from research in a military educational institution on Rio de Janeiro. A case study designed in 2017 , based on documentary sources, interviews and observations, showed the limits of this process in a school with such peculiar characteristics. Analyzes based on organizational models have strained the implementation of effective democratic management in this space, a fact that goes against proposal for the creation and expansion of civic-military elementary schools, instituted by the current Brazilian presidential governance and pointed out by Decree no. 9.465/2019.

Keywords: Democratic management. The militarization of teaching. Organizational theory. 
Resumen: El artículo aborda la gestión democrática en la enseñanza pública, problematizada a partir de la investigación realizada en una institución militar de enseñanza en Rio de Janeiro. Un estudio de caso realizado en 2017, respaldado por fuentes documentales, entrevistas y observaciones, señaló los límites de este proceso en una escuela con características tan peculiares. Los análisis basados en modelos organizacionales han forzado la implementación de una gestión democrática efectiva en este espacio, hecho que va al encuentro de la propuesta de creación y expansión de escuelas cívico-militares de educación básica, instituida por el actual gobierno presidencial brasileño y señalada por el Decreto no. 9.465 / 2019.

Palabras clave: Gestión democrática. Militarización de la enseñanza. Teoría organizacional.

\section{INTRODUÇÃO}

A Constituição Federal de 1988, em um período de reabertura políticodemocrática, logo após o fim da Ditadura Militar, definiu a "gestão democrática do ensino público, na forma da lei” (BRASIL, 1988), no Art. 206, Inc. VI, como um de seus princípios. Oito anos depois, em 1996, no Art. $3^{\circ}$, Inc. VIII, a Lei de Diretrizes e Bases da Educação Nacional reiterou esse princípio e, nos artigos 14 e 15, apresentou determinações no tocante a essa gestão:

Art. 14. Os sistemas de ensino definirão as normas da gestão democrática do ensino público na educação básica, de acordo com as suas peculiaridades e conforme os seguintes princípios: I - participação dos profissionais da educação na elaboração do projeto pedagógico da escola; II - participação das comunidades escolar e local em conselhos escolares ou equivalentes. Art. 15. Os sistemas de ensino assegurarão às unidades escolares públicas de educação básica que os integram progressivos graus de autonomia pedagógica e administrativa e de gestão financeira, observadas as normas gerais de direito financeiro público. (BRASIL, 1996).

Passadas três décadas após a promulgação do texto constitucional de 1988, a luta da sociedade brasileira pela legitimação e garantia desses direitos ainda perdura, em um país cujas distâncias, além de físicas, são materiais, econômicas, sociais e culturais.

Embora existam na Constituição Federal mais recente e na Lei de Diretrizes e Bases da Educação Nacional referências e princípios da gestão democrática e da qualidade do ensino público, essas disposições legais esbarram [...] na insuficiência em descrever e definir com maior precisão mecanismos que garantam ações administrativas educacionais efetivamente mais democráticas.

(PASSADOR; SALVETTI, 2013, p. 480). 
Em 2014, visando a orientar as ações institucionais em busca de uma gestão efetivamente democrática, que são amparadas pela Lei no 13.005 , passou a vigorar o Plano Nacional de Educação (PNE), o qual determinou diretrizes, metas e estratégias para a política educacional em um período de 10 anos, trazendo como meta a de número 19:

Assegurar condições, no prazo de 2 (dois) anos, para a efetivação da gestão democrática da educação, associada a critérios técnicos de mérito e desempenho e à consulta pública à comunidade escolar, no âmbito das escolas públicas, prevendo recursos e apoio técnico da União para tanto. (BRASIL, 2014).

Findo o prazo estabelecido pelo PNE, ainda é possível conceber a efetivação da gestão democrática nas redes públicas de ensino como um grande desafio, sendo evidentes as dificuldades de sua implementação no cotidiano escolar (FERNÁNDEZ, 2015). Partindo desse pressuposto, considerou-se oportuno refletir sobre os princípios que incidem na arena educacional e que fomentam a construção de uma perspectiva mais democrática.

Dos princípios desse modelo de administração, destacamos a questão da descentralização, compreendendo-a como indissociada da concepção que trazemos sobre autonomia. Enfatizamos as afirmações de Paro (2003) quanto à restrição desse princípio à distribuição de encargos e atribuições, devendo ser tratado enquanto autonomia que corrobora a constituição da identidade escolar, propiciando a redefinição do papel de cada um que atua na comunidade. Supomos que essa concepção de descentralização e, consequentemente, de autonomia, possa favorecer o enaltecimento de projetos contextualizados com a realidade, ao contrário de propostas homogeneizantes, ecoando discursos e prioridades que se fazem necessários.

Paro (2003) considera três categoriais de provimento ao cargo de gestor escolar nas escolas públicas, a saber: nomeação, concurso e eleição. $\mathrm{O}$ autor salienta que a primeira categoria traz consigo as marcas do clientelismo político, ainda muito presente nos sistemas de ensino brasileiros. Quanto à categoria concurso, ele acrescenta que suas principais virtudes são a "objetividade, a coibição do clientelismo e a possibilidade de aferição do conhecimento técnico do candidato" (PARO, 2003, p. 19). No tocante à eleição de diretores, esse seria o mecanismo mais favorável para o provimento do cargo de gestor, embora ressaltando que a escolha feita dessa forma não seria a solução para todos os problemas, apesar de se constituir como um dos fatores para esta democratização.

Ainda sobre a perspectiva de uma gestão democrática, acrescenta-se que o sistema que oportuniza a eleição de diretores precisa contemplar políticas que proporcionem uma estrutura adequada. Para tal, são fundamentais órgãos 
colegiados que desenvolvam de forma articulada os projetos políticos pedagógicos em que alunos, comunidade, professores e demais profissionais estejam inseridos. O mecanismo desses órgãos, constituído em um processo democrático nas decisões escolares, assume um lugar privilegiado de resgate de espaços para debates.

$\mathrm{Na}$ discussão sobre gestão, realçamos a importância das relações entre a liderança do diretor, o clima escolar e o desempenho dos alunos. Sobre esses aspectos, Oliveira e Waldhelm (2106) trazem a percepção dos professores de escolas municipais e estaduais do Rio de Janeiro, fazendo uma correlação entre gestores e ambientes propícios à aprendizagem dos alunos, sobretudo quanto à “Gestão democrática, mobilização comunitária e fortalecimento da equipe, que parecem contribuir para promover o maior envolvimento dos professores nas atividades escolares, favorecendo o aprendizado escolar dos alunos." (OLIVEIRA; WALDHELM, 2016, p. 838).

Dialeticamente, a atual governança presidencial brasileira, centro de recorrentes e acirrados debates, vem incidindo holofotes e marcando apontamentos que se distanciam das perspectivas desse modelo de gestão, além de reatar a questão da militarização das escolas públicas como mecanismo para conter a indisciplina e também oferecer melhorias na qualidade da educação. Através disso, o Ministério da Educação (MEC) vem pretendendo obter, voluntariamente, maior adesão de estados e municípios ao molde, mediante a oferta de recursos para a implantação de escolas em que militares e educadores compartilhem a gestão.

Algumas localidades já anunciaram que pretendem implantar ou ampliar a oferta de ensino em escolas militarizadas, entre elas aparecendo algumas dos estados do Rio de Janeiro, Roraima, Sergipe e Bahia. Há, ainda, estimativas que realçam a existência de cerca de 120 escolas públicas militarizadas em pelo menos 17 estados, entre as quais 60 estão concentradas em Goiás. Uma das metas anunciada pelo agora Presidente da República, Jair Bolsonaro, durante sua campanha eleitoral, foi a de instalar, pelo menos, uma unidade desse tipo em cada unidade da federação ${ }^{1}$.

Em 02 de janeiro de 2019, dia seguinte à posse presidente, foi publicado o Decreto 9.465/2019, que alterou a estrutura do MEC e criou a Subsecretaria de Fomento às Escolas Cívico-Militares. Sua função, apresentada no Art. 11, Inc. XVI, é "promover, fomentar, acompanhar e avaliar, por meio de parcerias, a adoção por adesão do modelo de escolas cívico-militares nos sistemas de ensino municipais, estaduais e distrital" (BRASIL, 2019). O decreto termina não trazendo Informações extraídas de: https://www.revistaeducacao.com.br/militarizacao-das-escolas/. Acesso em: 18 ago. 2019. 
especificações quanto às características do novo modelo de escola, embora seu artigo 16 deixe claro que os programas didático-pedagógicos e o sistema de gestão serão desenvolvidos pela referida subsecretaria.

Com base nessas considerações, pretende-se com este artigo debater alguns aspectos da militarização nas escolas, a partir de um estudo de caso realizado no segundo semestre de 2017. Parte-se do pressuposto de que essa militarização faz parte de um projeto hegemônico e conservador que coloca em risco a permanência dos direitos fundamentais e dos preceitos constitucionais, dentre eles, o direito à educação, como definida e defendida na Carta Magna. A partir disso, tencionaremos tal processo junto às questões que sustentam instâncias democráticas da/na gestão escolar, verificando desafios que lhe são subjacentes.

Como subsídios teóricos, para pensar a organização pesquisada, utilizaremos Lima (2008). O autor nos apresenta modelos de organização para o estudo escolar, auxiliando-nos a compreender que cada escola é uma unidade, mesmo estando inserida em um sistema maior. Cada escola, a fim de atingir os seus objetivos, possui princípios e procedimentos relacionados à ação de coordenar os envolvidos no processo educativo, que precisam ser compreendidos de forma heurística. Com esse olhar, é que o pesquisador, dentro de uma vasta panóplia de modelos oferecidos pela Teoria Organizacional, apresenta-nos o burocrático racional, o político, o de ambiguidade e o cultural, que, resumidamente, nos coloca:

\footnotetext{
No que diz respeito ao modelo burocrático racional, este tem sido um modelo muito aplicado à escola enquanto organização, na qual a cultura registra uma perspectiva de integração bastante profunda e coesa, dado que a racionalidade que caracteriza o modelo impede outras perspectivas. O modelo político de interpretação das organizações pareceu-nos relevante na economia deste trabalho atendendo à diversidade de interesses e objetivos e à 'racionalidade política' evidenciada pelos atores, isto é, uma racionalidade dirigida segundo a sua própria visão de organização. No que toca ao modelo da ambiguidade, este parece-nos abarcar algumas metáforas e imagens onde se procuram analisar práticas que, efetivamente, ocorrem nas organizações escolares. Por fim, o modelo cultural que confere um sentido eminentemente simbólico às organizações e que vai servir de suporte capital ao nosso trabalho. (LIMA, 2008, p. 31).
}

A partir do exposto, analisamos algumas características da escola que constituiu o campo, a fim de compreender quais seriam os modelos presentes na sua organização. As reflexões sobre clima escolar e o papel da gestão institucional estiveram, por sua vez, pautadas, principalmente, nos escritos de Oliveira e Waldhelm (2016) e Amaral (2016). 


\section{O CONTEXTO DA ANÁLISE}

No segundo semestre de 2017, iniciamos as observações que contribuíram para a caracterização da imagem de uma instituição militar de ensino. Partindo de uma visão disseminada e de senso comum, na qual processos democráticos e instituições militares são incongruentes, analisamos em que medida nesse contexto, democracia e gestão poderiam dialogar: Seria possível pensar em gestão democrática nesse lócus?

O campo pesquisado, cuja fundação ocorreu em 1960, tendo como principal objetivo educar/formar os filhos de civis e militares de uma Força Armada, situa-se na zona norte da cidade do Rio de Janeiro. À época da coleta de dados, a escola atendia a uma média de 1000 alunos, nos turnos da manhã e tarde, do $1^{\circ}$ ano do Ensino Fundamental até o $3^{\circ}$ ano do Ensino Médio. Dentre os discentes, mais de $50 \%$ eram dependentes de civis que não se enquadravam no perfil para o qual a instituição foi criada ${ }^{2}$ (BRASIL, 2003). Além da Educação Básica, oferecia cursos preparatórios para o Exame Nacional do Ensino Médio (ENEM), para instituições militares e, ainda, o Curso Técnico de Enfermagem.

O regime de subordinação da escola é respaldado por um parecer de 1981, quando o então Ministério da Educação e Cultura, tratando da regulação do ensino militar por lei específica, situa-o fora do alcance do MEC e, consequentemente, das Secretarias e Conselhos Estaduais de Educação. Isso significa dizer que a escola não sofria interferências (no sentido de fiscalização) e também não possuía dotação orçamentária vinda desse Ministério. A Força Armada, portanto, era quem mantinha o funcionamento da escola há quase 60 anos, contando também com a contribuição voluntária por parte das famílias dos alunos, no valor de $\mathrm{R} \$$ 100,00 mensais.

O quadro de professores era composto por servidores públicos federais (alguns tendo ingressado via concurso, outros, não), militares de carreira que tinham alguma formação relacionada à área educacional e estavam lá desviados de função e, ainda, militares do quadro temporário, que entraram por processo seletivo específico para sua área de atuação, mas que só ficavam na instituição por um período máximo de oito anos.

Sua área patrimonial é de 20 mil metros quadrados e a área construída ultrapassa 10 mil metros quadrados, o que evidencia o potencial estrutural, composto à época por: 53 salas, biblioteca, auditório, sala de vídeo, sala de

2 O ingresso de alunos não dependentes de militares teve início em 2003, por ocasião da assinatura de um Termo de Ajuste de Conduta do Ministério Público Federal. O mesmo Termo estabeleceu que a instituição não poderia cobrar uma mensalidade obrigatória, o que tornou voluntária a contribuição mensal das famílias dos estudantes. 
música, sala de leitura, laboratórios de física, química, biologia, informática, enfermagem, salas de artes plásticas, enfermaria, refeitório (os alunos recebem lanche diariamente), sala de fonoaudiologia, vestiários, cantina, papelaria, campo de futebol, pista de atletismo, ginásio poliesportivo, quadra de esportes, pátio com horta, etc. Apesar de toda essa infraestrutura, dificilmente encontrada numa instituição pública, vale ressaltar que ainda existiam problemas no tocante às questões de acessibilidade e ventilação dos espaços.

O Índice de Desenvolvimento da Educação Básica (IDEB) ${ }^{3}$ estava acima das médias observadas e projetadas para as escolas públicas do Rio de Janeiro, o que, dentre outros fatores, fazia com que a procura por matrículas na instituição fosse alta, incluindo moradores de outros municípios. Em 2015, por exemplo, o IDEB das turmas de quinto ano foi 6,9 enquanto a meta observada e projetada no município do Rio de Janeiro foi 5,6. No mesmo período, as turmas de nono ano atingiram nota 5,9 no IDEB, na medida em que a meta observada foi 4,4 e a projetada 5,9 .

\section{PROCEDIMENTOS METODOLÓGICOS}

Em outubro daquele mesmo ano, 2017, estivemos no local com o objetivo de conhecer o espaço, realizar entrevistas previamente agendadas e conversar informalmente com diferentes atores sociais, inclusive obtendo acesso a documentos da escola que, após serem analisados, subsidiaram a composição dos registros. Esta pesquisa está afinada com o que Lüdke e André descrevem como estudo de caso, já que nos possibilitou uma interpretação contextualizada, que buscou revelar as múltiplas dimensões presentes, enfatizando "a complexidade natural das situações, evidenciando a inter-relação dos seus componentes" (LÜDKE; ANDRÉ, 2005, p. 19).

Um dos procedimentos utilizados na coleta de dados foram as entrevistas semiestruturadas, gravadas com a autorização prévia dos participantes. Manzini (1991) nos coloca que esse tipo de entrevista está focalizada em um assunto sobre o qual confeccionamos um roteiro com perguntas principais, complementadas por outras questões inerentes às circunstâncias momentâneas à entrevista. Ainda segundo ele, as entrevistas semiestruturadas podem fazer emergir informações de forma mais livre, não ficando as respostas condicionadas a uma padronização de alternativas. 
Foram entrevistados quatro professores, sendo dois deles civis e dois militares que lecionavam as seguintes disciplinas: Filosofia, Matemática, Geografia e Enfermagem. Um dos entrevistados também era presidente da Associação de Pais, já que seu filho era aluno da instituição. Para fins deste artigo, com o intuito de proteger a identidade dos sujeitos, os componentes do grupo serão nomeados P1, P2, P3 e P4, respectivamente.

Além das entrevistas realizadas, tivemos conversas informais que, por sua vez, foram curtas, com perguntas mais pontuais e nos permitiram um registro de observação. Participaram desse momento duas alunas, um secretário escolar, o diretor pedagógico e o diretor administrativo. O diretor geral da escola, antecipadamente, permitiu-nos livre acesso aos espaços e documentos institucionais.

Além das entrevistas, utilizamos como instrumento de coleta de dados a análise documental que, de acordo com Lüdke e André (2005), constitui fonte poderosa de onde podem ser retiradas evidências que fundamentam afirmações e declarações do pesquisador, representando uma fonte natural de informação. Assim, a análise do Projeto Político Pedagógico, Regimento Interno, Regime Disciplinar, além dos documentos já disponíveis na página da internet, possibilitou-nos inferências e corroborou de maneira significativa com a pesquisa.

\section{A ESCOLA COMO ORGANIZAÇÃO: ESPAÇOS DE MANIFESTAÇÃO, RELAÇÕES ENTRE OS ATORES, CLIMA INSTITUCIONAL E OS DOCUMENTOS ESCOLARES}

Pensar na escola que constitui o campo enquanto organização requer que destaquemos a opção que adotamos para analisá-la, de forma "complexa e polifacetada", admitindo as variadas influências e tradições disciplinares que ela compreende, ou seja, uma "organização em ação" (LIMA, 2011). Nessa perspectiva, dialogamos com os dados obtidos nas entrevistas, conversas informais e observações, reiterando a importância de se investigarem não apenas aspectos aparentes, mas compreender a realidade organizacional para além. Esse fato corrobora as afirmações de Lima (2011), quando afirma que "a escola não é um 'dado' dado, uma realidade empírica de primeira ordem que seja passível de 'captação' imediata, sem a mediação de teorias e conceitos, implícitos ou explícitos” (LIMA, 2011, p. 148, grifo do autor).

Adentrando as relações escola-comunidade, o "Regime disciplinar provisório do corpo discente e orientações gerais sobre os direitos e deveres dos responsáveis", quanto ao título "Direitos dos alunos", sustentava que: "são direitos dos alunos participar das associações e órgãos cocurriculares, desde que 
as normas de funcionamento tenham sido aprovadas pela Direção". No título seguinte, "Deveres dos alunos", era mencionado que cabe ao aluno "participar de todas as atividades promovidas pela escola, para as quais for convocado". O texto ainda mencionava, no título "Deveres dos Responsáveis", que compete a eles "participarem das reuniões para as quais forem convocados".

P4 informou que as instâncias de participação na escola começaram com as 'Rodas de Conversa' junto aos pais. Esses encontros também denominados 'Grupos de Reflexão’ eram coordenados por uma psicóloga e tinham por objetivo "dar voz aos pais". Além disso, existia o projeto 'Família na Escola' que levava os pais para os cursos, além de bazares promovidos pela Associação de Pais. Segundo informações do professor, essa Associação trazia muitos pais para o espaço escolar e, "mesmo que não fosse uma participação de todos, quem participava, participava efetivamente". P4 considerava que o colégio poderia fazer muito mais trabalhos com a comunidade do entorno, já que nas proximidades havia hospital, escolas municipais e creches, inclusive mencionando as ações que aconteciam através do Curso de Enfermagem.

A participação da Associação junto aos professores acontecia com aqueles que "acolhiam e tinham disponibilidade de escuta". Cada série contava com um orientador psicopedagógico e esse profissional tentava fazer esse papel. Sendo assim, diante das queixas dos responsáveis, a orientação era que eles pudessem resolvê-las, primeiramente junto ao Serviço de Orientação Psicopedagógica (SOP) e, caso fosse necessário, poderiam percorrer outros caminhos junto à Associação. No que compete à comunidade, o mesmo documento de Regime Disciplinar, no Título "Direitos dos Responsáveis", estabelecia que os responsáveis têm direito a "dar sugestões, por escrito, à Direção da escola, com o intuito de melhorar o padrão e a eficiência do mesmo" e "quando, convidados, participarem de eventos, reuniões e de grupos de trabalho promovidos e organizados pela Direção".

A Associação de Docentes, de acordo com P2, era, pela gestão, "impedida de se reunir dentro da escola". O professor, inclusive, mencionou não existir ouvidoria, sendo o SOP o principal canal de atendimento formal para atendimento dos pais. Esse atendimento dependia, muitas vezes, do profissional que estava lá e como daria prosseguimento à demanda e, ainda, com a coordenação de turno, que atuava mais nas questões disciplinares e, segundo o entrevistado, era muito valorizada na escola. Para P2, a manifestação se dava de forma individual e ele nos sugeriu questionar a Associação de Pais como isso se articulava de forma coletiva. O docente ainda ponderou a importância de que fosse averiguado o fato de a Associação ter representatividade e legitimidade, se nela existia democracia de forma a realmente representar o coletivo de pais dos alunos e suas demandas ou se estaria restrita à apresentação de propostas a eles. 
$\mathrm{Na}$ fala de vários atores apareceu claramente a menção da importância atribuída ao reconhecimento externo dessa escola, valorização esta traduzida por P4 como "orgulho pelo uso do uniforme", sobretudo através da visibilidade em eventos dos quais eram constantemente convidados a participar. Essa postura também converge com o reconhecimento obtido por meio da aprovação de mais de 70\% dos alunos em concursos públicos, sobretudo o Curso Técnico de Enfermagem, intitulado como "menina dos olhos".

Esse mesmo professor afirmou não existir Grêmio e o que havia em termos de organização dos alunos eram as 'Comissões de Formatura'. Em todas as classes havia um aluno representante e um pai representante, embora as reuniões com os alunos representantes fossem inexistentes. Entretanto, com os pais, a Associação realizava dois encontros anuais. Além disso, havia o 'Centro de Memória' da escola, contendo uniformes antigos, fotografias e objetos que remetiam à história da instituição. $\mathrm{Na}$ entrevista com $\mathrm{P} 2$, houve menção a existência do Grêmio, sempre sob a tutela do SOP, portanto, sem autonomia.

No que se refere ao provimento do cargo de Diretor Geral, o Regimento Interno propunha que este fosse Coronel da Força Armada, da ativa ou da reserva, ou servidor civil com regime de dedicação exclusiva, designado pelo órgão militar. A designação para esse cargo era para um período de dois anos ou, de acordo com os interesses da Administração, podendo haver prorrogação no prazo. Ouvindo os atores, a gestão foi mencionada como detentora de um 'poder unilateral', de modo que a queixa dos docentes deteve-se ao fato de não possuírem contato com os gestores, para externar demandas e reivindicações. Portanto, o espaço poderia ser caracterizado como um movimento de tensões e conflitos, nem todos aparentes.

O processo de eleição para a Direção transitou em uma escala democrática, passando de uma escolha 'verticalizada', feita pela própria Força Armada, para uma consulta à comunidade, retornando no momento da pesquisa, à escolha feita pelo órgão mantenedor. Os gestores possuíam licenciaturas em diversas áreas e o Diretor Geral ficava incumbido de escolher os demais (administrativo e pedagógico). O Diretor Geral era subordinado ao Supervisor Militar que fazia conexão entre a escola e o Comando da Força Armada. Acrescentando, sobre a problemática da formação dos gestores que se assemelha ao que foi caracterizado por essa pesquisa, Amaral (2016) aponta que 
A função de diretor de escola, no Brasil, foi se constituindo como parte da consolidação da estrutura hierárquica e burocrática da educação brasileira e, até os dias atuais, nem sempre é exercida por profissionais com formação técnica, que tenham sido avaliados pelos poderes públicos de modo a certificar competências para o exercício da gestão escolar ou, ainda, que tenham sido escolhidos pela comunidade escolar. (AMARAL, 2016, p. 27).

Esse formato de escolha foi bastante criticado pelos docentes, que trouxeram alegações de que não havia uma construção coletiva, por meio da participação de todos os envolvidos no processo educativo, não havendo um fluxo comunicativo eficiente entre as diferentes esferas e setores. Só os gestores 'tomavam as decisões', havendo uma reunião semanal entre os coordenadores de disciplinas e o Diretor Pedagógico. Esse era o único espaço de participação docente e, após o encontro, o diretor repassava as decisões aos demais membros da gestão.

De acordo com a entrevista de P2, existiam reuniões com os professores e com os coordenadores de disciplina e as instâncias de deliberação coletiva não aconteciam. Havia um organograma definido pelo regimento interno proposto pelo órgão mantenedor. As relações hierárquicas aparentavam ser conflituosas, sobretudo por se tratar de uma composição híbrida nos cargos de professores civis e militares - fomentando a premissa de que um dos grupos (militares) teria mais acesso às reuniões do que o outro (civis).

Analisamos também algumas características do local, a fim de compreender quais eram os modelos organizacionais presentes em sua estrutura. O primeiro modelo identificado foi o burocrático racional. Sua escolha está pautada nas características propostas por Lima (2008) e que foram percebidas a partir das entrevistas, conversas e documentos. São elas: o modelo era apreciado por uns e repudiado por outros; havia uma clara divisão de tarefas, hierarquia de poderes, regras e regulamentos precisos; existia uma especificação de forma minuciosa das funções que cada funcionário tinha de desempenhar, planejar e controlar; aos atores educativos estaria reservada uma função passiva, de meros 'executantes de papéis' na base de um 'determinismo normativo'; havia certa resistência à mudança; e ficava clara a exibição de sinais de autoridade.

O segundo modelo foi o cultural, justificado também pelas características apresentadas em Lima (2008), a saber: história, identidade, linguagem própria, símbolos e modelos de comportamento; um percurso que individualizava e particularizava a instituição; a escola era dotada de um simbolismo substancialmente distinto de qualquer outra instituição; a preocupação constante do gestor era orientada por aspectos simbólicos; era recorrente apontar a cultura como chave para a eficácia, a qualidade e a excelência. 
Dentro do debate sobre gestão, as articulações tecidas no/com o Projeto Político Pedagógico (PPP) das instituições escolares são norteadoras, visto tratarse de um documento que abarca o conjunto de metas que se quer alcançar dentro desses espaços. É fato que muitas unidades educacionais caminham sem ele, mas nos intriga saber para qual direção avançam, já que

\begin{abstract}
Em muitos dos PPPs analisados, nunca se passa à formulação do plano talvez porque o escasso tempo escolar disponível para o debate coletivo já se esgotou na discussão do marco referencial - e, portanto, os conflitos e os problemas institucionais não chegam a ser adequadamente debatidos. A ausência da negociação que decorreria da formulação do plano, portanto, gera um projeto não apenas sem participação efetiva dos diferentes sujeitos escolares, mas também sem a devida contratualização entre as pessoas envolvidas no processo educacional. (FERNÁNDEZ, 2015, p. 51).
\end{abstract}

O PPP do colégio investigado havia sofrido a última atualização no ano de 2013/2014. Vários itens estavam desatualizados: o histórico, o acesso aos meios de transporte ao colégio, a estrutura física (houve novas construções) e a capacidade de atendimento (número de turmas também não era mais o mesmo). Além disso, alguns itens eram a compilação, na íntegra, de outros documentos institucionais. No que se refere aos recursos humanos e ao sistema de avaliação, tratava-se de uma compilação do Regimento. O diagnóstico contendo os problemas e propostas apresentava os quatro pilares definidos pela Organização das Nações Unidas para a Educação, a Ciência e a Cultura (UNESCO); uma lista extensa de êxito dos alunos em concursos e premiações estava elencada nesse subtítulo. Foram apresentadas dez metas pedagógicas com proposições gerais, não contendo um cronograma que especificasse de que forma seriam executadas.

Segundo os entrevistados, a elaboração do PPP se deu de forma unilateral, sem a participação do corpo docente/discente e/ou dos demais membros da comunidade escolar. Relataram-nos que, em 2015, um grupo de trabalho foi montado para esse fim com reuniões periódicas por oito meses. Ao final das reuniões houve a proposta que o PPP fosse construído por meio de um congresso com representantes de cada categoria. Sobre esse assunto, o Diretor Pedagógico, em conversa informal, disse-nos que a construção do novo documento foi interrompida até que a subordinação da escola fosse definida e, assim, não houvesse 'desperdício de trabalho' ipsis litteris. Tal fato se dava porque a Força Armada passava por uma reestruturação quanto aos colégios que estariam sob sua subordinação. 


\section{CONSIDERAÇÕES FINAIS}

Primeiramente, é preciso dizer que não tivemos o intuito de tecer críticas às instituições militares de ensino, tampouco exaltar determinado tipo de educação, em detrimento de outra. Ao contrário, esse artigo buscou dialogar com o trajeto que percorremos na pesquisa, permitindo que realizássemos algumas inferências sobre esse contexto escolar que, em se tratando de um estudo de caso, essencialmente reuniu pontos de vista conflitantes presentes na dada situação social (LUDKE; ANDRÉ, 2005).

Certas também de que o problema da educação no país não pode ser sintetizado pela questão disciplinar, como a visão militar e o discurso presidencial repercutem, defendemos que qualquer medida educacional sem o envolvimento da comunidade escolar está fadada ao fracasso. Indo além, por acreditarmos nos avanços alcançados no percurso histórico do país - a Constituição Federal, a LDBEN e mais recentemente o PNE - é que problematizamos como tem-se dado a gestão de uma instituição militar de ensino, sobretudo em um momento político, como o da publicação do decreto 9465/2019 (BRASIL, 2019), visto que, seguramente, uma sociedade mais justa perpassa por uma escola democratizada e democratizadora.

Desse modo, a investigação possibilitou que identificássemos pressupostos que ancoram os modelos organizacionais, tal como havíamos objetivado com o desvendamento e a compreensão de alguns aspectos mais ocultos da organização escolar, permitindo o acesso a uma leitura explicativa dos meandros do funcionamento da escola.

Quanto aos limites e perspectivas para uma gestão democrática, foi possível perceber uma gestão em grande parte centralizadora e que não supria as necessidades de todos os processos, como as atividades pedagógicas, por exemplo, tendo o corpo docente autonomia na construção das abordagens para as diferentes disciplinas do currículo escolar. Acrescentamos que o modelo militarizado da gestão, o qual aparece como solução para a questão da violência no contexto educacional, atualmente ainda encontra muitos adeptos pelas propostas de melhoria no rendimento dos alunos, ancorados na notável ideia de diminuição das taxas de reprovação e na introdução da disciplina militar fundamentada na hierarquia e disciplina, chamando a atenção daqueles que anseiam pela segurança nas escolas.

A pesquisa desenvolvida nos permitiu inferir que a instituição não sintetizava um modelo opressor, onde a hierarquia impedia qualquer racionalidade ou atitude mais criativa, apesar de, obviamente, não ser uma escola onde se dava de maneira explícita e completa o que poderíamos chamar de gestão democrática. 
Em suma, foi possível verificar que existiam limites claros para que a gestão democrática se concretizasse no seio desse espaço e, apesar do anseio de uma parcela de professores por essa demanda, não foi possível identificar um desejo para tanto, por parte da Direção, à época. Isto terminou tornando perceptível a não intenção do cumprimento do que é preconizado pela legislação.

Assim, defrontamo-nos com uma instituição que sintetizava êxito em seus resultados, constituindo um modelo de inspiração a tantas outras. Apesar disso, no que tange à discussão sobre gestão democrática, mostrou-se com dados consistentes que se distanciam da perspectiva de uma efetiva gestão democrática, tal como a que trazemos para o debate deste artigo.

\section{REFERÊNCIAS}

AMARAL, D. P. do. Mérito, desempenho e participação nos planos municipais de educação: sentidos da gestão democrática. Revista on line de Política e Gestão Educacional, Araraquara, SP, v. 20, n. 3, p. 385-404, set./dez. 2016. Disponível em: http://seer.fclar.unesp.br/rpge/article/view/9532. Acesso em: 27 jul. 2019.

BRASIL. Constituição da República Federativa do Brasil de 1988. Brasilia, DF: Senado Federal, 1988. Disponível em: http://www.planalto.gov.br/ccivil_03/ constituicao/constituicao.htm. Acesso em: 27 jul. 2019.

BRASIL. Lei $\mathrm{n}^{\circ}$ 9.394, de 20 de dezembro de 1996. Estabelece as diretrizes e bases da educação nacional. Diário Oficial da União: seção 1, Brasília, DF, ano 134, n. 248, p. 27833, 23 dez. 1996.

BRASIL. Ministério Público Federal. Procuradoria da República no Estado do Rio de Janeiro. Termo de Ajustamento de Conduta, assinado em 04 de dezembro de 2003.

BRASIL. Lei no 13.005, de 25 de junho de 2014. Aprova o Plano Nacional de Educação - PNE e dá outras providências. Diário Oficial da União: seção 1 Edição Extra, Brasília, DF, ano 151, n. 120-A, p. 1, 26 jun. 2014. 
BRASIL. Decreto no 9.465, de 02 de janeiro de 2019. Aprova a Estrutura Regimental e o Quadro Demonstrativo dos Cargos em Comissão e das Funções de Confiança do Ministério da Educação, remaneja cargos em comissão e funções de confiança e transforma cargos em comissão do Grupo-Direção e Assessoramento Superiores - DAS e Funções Comissionadas do Poder Executivo - FCPE. Diário da União: seção 1- Edição Extra, Brasília, DF, ano 157, n. 1-B, p. 6, 02 jan. 2019.

FERNÁNDEZ, S. Projeto Político Pedagógico e cotidiano escolar: retrospectivas, deslocamentos e possibilidades. In: AMARAL, D. P. do. Gestão Escolar pública: desafios contemporâneos. Rio de Janeiro: Fundação Vale, UNESCO, 2015.

LIMA, L. C. Administração Escolar: estudos. Porto: Porto Editora, 2011.

LIMA, L. C. A escola como organização educativa. São Paulo: Cortez, 2008.

LÜDKE, M.; ANDRÉ, M. E. D. A. Pesquisa em educação: abordagens qualitativas. São Paulo: EPU, 2005.

MANZINI, E. J. A entrevista na pesquisa social. Didática, São Paulo, v. 26/27, p. 149-158, 1991.

OLIVEIRA, A.; WALDHELM, A. Liderança do diretor, clima escolar e desempenho dos alunos: qual a relação? Ensaio, Rio de Janeiro, v. 24, n. 93, p. 824-844, out./dez. 2016.

PARO, V. H. Eleição de diretores: a escola pública experimenta a democracia. São Paulo: Xamã, 2003.

PASSADOR, C. S.; SALVETTT, T. S. Gestão escolar democrática e estudos organizacionais críticos: convergências teóricas. Educação \& Sociedade, Campinas, v. 34, n. 123, p. 477-492, abr./jun. 2013.

PICARELLI, Maria. Militarização das escolas públicas: soldado ou cidadão?. Revista Educação, São Paulo, n. 257, 29 abr. 2019. Disponível em: https:/ /www. revistaeducacao.com.br/militarizacao-das-escolas/. Acesso em: 18 ago. 2019. 
CAROLINA BARREIROS DE LIMA é Mestre em Educação e licenciada em Matemática pela Universidade Federal do Rio de Janeiro. Atua como Assessora no Instituto de Educação e Pesquisa do Ministério Público do Estado do Rio de Janeiro.

E-mail: carol.barreiros.lima@gmail.com

NATALIA BARBOZA NETTO é Mestre em Educação e licenciada em Pedagogia pela Universidade Federal do Rio de Janeiro. Atua como professora no Ensino Fundamental da Secretaria Municipal de Educação do Rio de Janeiro e na Educação Infantil de uma escola privada

E-mail: natnetto1@gmail.com

JANAINA MOREIRA PACHECO DE SOUZA é Doutora em Educação pela Universidade do Estado do Rio de Janeiro; Mestre em Educação pela Universidade Estácio de Sá; Licenciada em Letras - Português/Literaturas pelo Centro de Ensino Superior de Juiz de Fora e em Pedagogia. Atua como Professora de Língua Portuguesa no Colégio Brigadeiro Newton Braga - Força Aérea Brasileira.

E-mail: janamoreira91@gmail.com 